\title{
Breast Cancer disease and Heavy Metal: Cadmium as Key in "Medical Geology"
}

ZIARATI P. ${ }^{1}$, HOCHWIMMER B. ${ }^{2}$, LAMBERT BROWN D. ${ }^{3}$, MORADI M. ${ }^{4}$ and ${ }^{*}$ CRUZ-RODRIGUEZ L. $5,6,7$

\author{
${ }^{1}$ Head of Nutrition and Food Sciences Research Center, Tehran \\ Medical Sciences, Islamic Azad University, Tehran, Iran \\ ${ }^{2}$ CEO, B. Hochwimmer \& Asso. Pty Ltd, Consultants in Mineral \\ Exploration, Mining and Environmental Geology. Albury, NSW, \\ Australia.
}

${ }^{3} C E O$, Family Physician, FCMC \& ExCELab Co. Ltd, Jamaica.

${ }^{4}$ Department of Cell \& Molecular Biology, Faculty of Biological Sciences, Kharazmi University, Tehran, Iran

${ }^{5}$ ExCELab Co. Ltd., Manager Director of Environmental Biotechnology Department., Jamaica.

${ }^{6}$ CEO, ELIDAN Dynamic LLC, Tampa, FL, 33619, USA.

CEO, ELIDAN genome SAS, 1 avenue du Lycée, 77130

\author{
"Correspondence author \\ Dr. Luis CRUZ-RODRIGUEZ \\ Manager Director of Environmental Biotechnology \\ Department \\ ExCELab Co. Ltd \\ Jamaica \\ E-mail : ceo@elidan-genome.com, \\ luis.cruzrguez@gmail.com
}

Submitted : 26 March 2020 ; Published : 1 June 2020

Montereau Fault Yonne; France.

\begin{abstract}
Health problems arising from geological materials and processes are more common than most people believe. Geology may appear remote from human health. However, rocks are the fundamental building blocks of the Earth's surface, full of important minerals and chemical elements. Rock weathering and alteration products not only form our soils to support our crops but provide essential elements to build biology. Drinking water travels through rocks and soils as part of the water cycle, and much of the dust and gases contained in the atmosphere are of ultimate geological origin. Without this tectonic "rock cycle" connection to atmosphere and water, there can be no life. Human evolution is also intimately bound to geology. The African rift valley unique geology and metallogenesis is fundamental to the cradle of human evolution and expansion, both physiographically and bio-geochemically. Facilitated by an amplified oscillating mosaic environments climate, biology and geology, particularly in the last 2.6 Ma of the 30 Ma Cenozoic cooling and drying, hominoids were not only adapted to biological and climactic factors but also parent rockelements, including metal (loids) used to build their biological structures and functions. Numerous enzymes incorporate metal(loids) central to their catalytic functions. Over 1,200 are known to be involved in neurobiology alone, likely impacting evolution of Homo habilis to H. erectus, near doubling brain size, complexity and energy demand. Metalliferous enzyme homeostatic deregulation widely impacts health from cancer to neurological diseases. Pre-adapted to the African rift biogeochemistry mosaic, a far more skewed metalliferous anthropecen now adversely impacts metal homeostasis and our health. Concentrating on the Medical Geology of highly toxic cadmium $(C d)$, we explore its environmental relationship with Breast Cancer. We studied urinary Cd levels in 150 women with Breast Cancer (diagnosis age 20 to 69 years). Cd levels trend aggressive with different risk profile from later-onset disease "stage III". Conditional logistic regression was used to calculate odds ratios and 95\% confidence intervals. After correcting for differential calendar time of sample collection, statistically significant associations were observed between Cd levels and Breast Cancer risk amongst participants with localized breast cancer, Odds Ratio (OR): OR=1.35; 94\% CI: 1.21.8; $p=0.004$ and participants with regional/distal Breast Cancer: OR=1.81; 96\% CI: 1.4-2.4; $p=0.001$. We concluded, the association of Breast Cancer risk with Cd levels did not differ between participants treated by surgery and/or radiation ( $p \geq 0.05)$ only $O R=1.34 ; 93 \%$ CI: 1.0-1.5 and those treated with chemotherapy OR=1.35; 94\% CI: 1.0-1.6. Cd exposure probably related to the association between $\mathrm{Cd}$ and renal diseases, cardiovascular outcomes, cancer, especially Breast Cancer family history. Avoiding excessive metal(loid), including Cd, in all sources is advisable. These may include tattoo and or colorful cosmetics, Indian rice dietary habits, known higher in metal(loids) due to expensive local rice and smoking. We recommend women older than 40 years, particularly with family Breast Cancer history, to largely avail themselves of a plant based diet, along with adequate heavy metal ameliorating trace elements e.g. selenium, to drink anti-inflammatory herbal tea in daily diet, and non-smoking habits.
\end{abstract}

Keywords: Breast Cancer, Heavy Metal, Cadmium, Cd, Lifestyle, Medical Geology, Odds Ratio (OR) 
Introduction

According to previous studies in Iran, large scale industrialization is mainly responsible for general heavy metal concentration in the urbane and regional environments. This threatens not only to the physical well-being of individuals but endangers "human", existence physically, sociologically and psychologically. Its biogeochemical impacts on neuronal disease and synergistic concomitant violence in society and general poor health is especially critical for the aged, but also young population's aging simultaneously, impacting and stretching health services beyond its limits.

Added to this is the natural geological and geogenic and environments input of metal(loids). Metals in pathology are an ever increasing issue for health. This study on cadmium confirmed an association with localized Breast Cancer but of diffuse environmental pathway, cursory investigations of it could not be resolved well. Because of the narrow concentration difference, reliable knowledge of the metal content in various matrices is mandatory [1]. In organic materials the ICP-MS detection limit around $0.01 \mathrm{ppm} \mathrm{Cd}$ is likely to yield $\pm 100 \%$, but this precision improves markedly at just $0.05 \mathrm{ppm} \mathrm{Cd}$ [2].

Altogether this highlights the need for diverse practitioners, public and decision makes to be aware of Medical Geology, and a short review is provided of the field for this purpose. The field focuses on how the geological environment impacts health through geological-geogenic and anthropogenic remobilization of elements to biota and its pathological pathways to health issues.

Geological releases of cadmium to soil, surface and ground waters is diverse and even includes aerosols. Hydrothermal degassing emissions through fumarolic, diatreme and larger volcanic vents to atmosphere add significant $\mathrm{Cd}$ to the food chain. There are over 10,000 active volcanoes worldwide, many subsurface vent gasses and large quantities of aerosol metal species such as chlorides and sulphides that ligate cadmium continuously, aside from volcanic eruption additions. Aerosol emissions of lead alone from White Island volcano, NZ, are estimated to range up to $125 \mathrm{~kg}$ per day, along with up to $140 \mathrm{~kg}$ /day arsenic. Cadmium may be low in general volcanic rocks, typically for example White Island (0.05 ug.g-1); Yasur (0.12 ug.g-1) and Etna (0.9 ug.g-1). But aerosol emission enrichment factor can be exceedingly high, with 1281, 1197 and 8,176 recorded for White Island, Yasur and Etna volcanoes respectively. High emissions have been noted for other metals including antimony, indium, bismuth, and the deadly thallium,

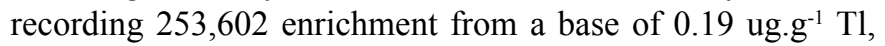
along with essential element selenium enriched 2,159,524 times its 0. 9ug.g-1 Se base from White Island. In contrast, aerosol copper is relatively depleted, suggesting deposition in the subsurface environment before degassing [3]. Mother Earth is not benign and sends us essential elements, such as selenium, along with metals negatively impacting health.

Anthropological cadmium emissions alone are estimated to be 30,000 metric tonnes per year to atmosphere and extensive industrial disseminations end up in soil, from galvanization and electro-plating, manufacturing of alloys, pigments and plastics [4]. Much Cd will also enter landfill groundwater's and surface waterways. The worlds ecosystems, agriculture lands and other $\mathrm{Cd}$ inventory of this highly toxic and carcinogenic metal is constantly building in nature linked to our food chain. Cd exposure to humans and its damage to health will therefore continue to increase for millennia, imparting endocrine dysfunction, liver and kidney toxicity, neurotoxicity, pulmonary issues and teratogenic impacts $[5,6]$.

There is therefore an urgent need to map and research the Medical Geology of cadmium in the food chain globally. Rice was one factor identified in this Breast Cancer study linked with cadmium [7]. Along with other metals vast lands of rice crops are affected, but the distribution is uneven. Spatial geologicalgeogenic PVM-models and similar strategies may provide mappable 'Medical Geology indicators' of essential elements or pollution when qualified biogeochemically, as "Geogenic Public Health Indices" (PVM-HI). Ideally, they and other indices, such as warfare and industrial metalliferous debris 'indices' may help produce "The Medical Geology Map of The Globe", supporting public health in developing countries and where epidemiological and metallogene supervision of it is sparse $[8,9,10]$.

We studied urinary $\mathrm{Cd}$ levels in 150 women with Breast Cancer (diagnosis age between 20-69 years), and 37 women as the control group, which tends to be more aggressive and have a different risk profile from later-onset disease. Conditional logistic regression was used to calculate odds ratios and $95 \%$ confidence intervals. After correcting for differential calendar time of sample collection, statistically significant associations were observed between $\mathrm{Cd}$ levels and Breast Cancer risk among participants with localized Breast Cancer, Odds Ratio (OR): $(\mathrm{OR}=1.35 ; 94 \% \mathrm{CI}: 1.2-1.8 ; \mathrm{p}=0.004)$ and participants with regional/distant Breast Cancer, $(\mathrm{OR}=1.81$; 96\% CI: 1.4$2.4 ; \mathrm{p}=0.001)$. The association of breast cancer risk with $\mathrm{Cd}$ levels did not differ between participants treated by surgery and/or radiation $(\mathrm{p} \geq 0.05)$ only $(\mathrm{OR}=1.34 ; 93 \% \mathrm{CI}: 1.0-1.5)$ and those treated with chemotherapy, $(\mathrm{OR}=1.35$; $94 \% \mathrm{CI}$ : 1.0 1.6).

Similar associations between Cd levels and Breast Cancer risk were observed among participants with localized breast cancer $(\mathrm{OR}=1.35 ; 94 \% \mathrm{CI}: 1.2-1.8 ; \mathrm{p}=0.004)$ and participants with regional/distant Breast Cancer $(\mathrm{OR}=1.81 ; 96 \% \mathrm{CI}$ : 1.4-2.4; $\mathrm{p}=0.001$ ). The association of Breast Cancer risk with Cd levels did not differ between participants treated by surgery and/ or radiation $(\mathrm{p} \geq 0.05)$ only $(\mathrm{OR}=1.34 ; 93 \% \mathrm{CI}: 1.0-1.5)$ and those treated with chemotherapy $(\mathrm{OR}=1.35 ; 94 \% \mathrm{CI}$ : 1.0-1.6).

\section{Diet and Lifestyle Factors $(n=150)$}

As we showed in Tables 1 and $\mathbf{2}$, no practical difference was found between cases and control regarding living or working in urban areas with, dietary habits and food $\mathrm{Cd}$ resources 
in Iranian daily regimen including rice, bread, dairies, tea, coffee, crops in recent (3 years) and past ( $>20$ years), smoking habits, smoking cessation, exposure to household chemicals, consuming $\mathrm{Cd}$ from household items such as plastic dishes and bottles and using water purification devices at home or consuming $\mathrm{Cd}$ as Cosmetic items such as eye shadows. Our studies show that women with dietary habits of Indian rice consummation have a non-significance result.

We confirm the same statistical results in individual study around dietary habits of bread, black tea and coffee consummation. Also, we can show that a Breast Cancer condition is not associated with Academic Education and Employed status in this Iran study. Finally, "Tattoo selection" and colorful cosmetics is not associates with age: women older than 40 years have the same statistical results than the younger group in age range of 20 to 40 years. The results of current studies revealed that chronic exposure to $\mathrm{Cd}$ probably related to the association between $\mathrm{Cd}$ and renal diseases, cardiovascular outcomes, cancer, especially Breast Cancer history in the family, Tattoo or colorful cosmetics, eating Indian rice in dietary habits (due to expensive local rice) [7].

We advise women, particularly those with family Breast Cancer history, to largely avail themselves of a plant based diet, along with adequate heavy metal ameliorating trace elements, e.g. selenium-zinc, drink herbal tea as part of their daily diet and adopt nonsmoking habits. Our advice is highly addressed to women older than 40 years. Good habits begin early though, and would yield significantly less early DNA and epigenetic damage that impacts late onset Breast Cancer.

\section{International Medical Geology Association (IIMGA)}

The newly formed (IMAG) is paving a way to greater Medical Geology awareness by first bringing scientists in developed and under developing countries together to address this global issue. One effective way they are doing this is by running international short training courses. Such courses have been highly successful in sharing the most recent information on the relationship between metal ions, trace elements, and their impact on environmental and public health. Course contents include environmental toxicology, environmental pathology, geochemistry, soil science, geoenvironmental epidemiology, extent, patterns and consequences of exposures to metal ions, analytical methods and pathology. Such activities will be extended to include research projects involving local scientists in the less developed countries, especially where there is a pressing need to tackle health issues arising from geology. The course content may provide a model for the combined training of geoscientists, biomedical health professionals, and decision makers in Medical Geology.

Medical Geology brings together Earth scientists and medical/ public health researchers to address health problems ultimately caused or exacerbated by geologic materials (rocks, minerals, waters, other fluids and gasses) and processes such as volcanic eruptions, earthquakes/tsunamis and atmospheric dust and polluting aerosols. It includes geological mineralization's that ultimately impacts soil, ground and surface drinking and irrigation waters, agricultural and biologically recycled gray waters, biota pollution, food and air quality.

We may also consider industrial products as part of "The Geological Anthropocene" and its geogenic remobilization of detrimental elements as a Medical Geology concern. From industrial and warfare debris, natural processes of geogenic remobilization of metal(loid) can change mobile mineral and elemental species to more dangerous forms, posing serious risk to soil, food bowl, water and air quality. Examples include methyl forms of mercury and arsenic and labile forms of chromium and water-soluble cadmium sulphate (CdSO4) easily taken up by plants.

\section{Review}

\section{Medical Geology History and it's Re-emergence}

Geology may appear remote from human health but problems arising from geological materials and processes are far more common than most people believe. Rocks are the fundamental building blocks of the Earth's surface, full of important minerals and chemical elements. Most elements are taken into the human body in air, food and water. Rocks are broken down by weathering processes to form the soils on which crops and animals are raised. Drinking water travels through rocks and soils as part of the water cycle, and much of the dust and some of the gases contained in the atmosphere are of geological origin [3, 8-12].

Without the rock cycle, that is the convection of rocks from the lithosphere to the mantle and back, and its connectivity with the water cycle and atmosphere, there can be no life.

Geology sustains the life of earth's people. Conversely the health of an estimated three billion people all over the globe is adversely affected by geology. This is mostly unknown to the public, even amongst health professionals, including nutritionists and doctors. A brief introductory overview is therefore provided. Earth and Health, or "Medical Geology", is concerned with the relationship between natural and anthropogenic geological factors and human and animal health as well as improving our understanding of the influence of environmental factors on the temporal and geographical distribution of such health problems and their controls [13, 14].

In doing so, Medical Geology attempts to trace diverse geological releases of metal(loids) and minerals, their geogenic mobilization species changes and concentrations to environment, biota and humans leading to acute and chronic pathology. This may also involve investigating molecular pathways to discriminate cause and effect of such diverse health issues amidst confounding biological and cultural factors. The Medical Geology field is very diverse and multidisciplinary. For instance it has been suggested human corona viral out break may have zoonotic linkages to geology impacting soil 
repositories and mobilization that may explain historically similar sequential viral outbreaks [15].

Such information, vital to the general public, is essential for geologists and their specialized earth scientist colleagues, medical doctors and allied health professionals, planners and decision makers, environmental engineers and scientists, biologists, agronomists, and chemists, to name just a few if the negative health effects of geology and its anthropogenic products and processes are to be environmentally and bodily avoided, treated and mitigated effectively $[4,9,10,11,16,17]$. Solutions to such environmental causes of health problems will be found by integrating Earth sciences with these specialties. More than ever diverse expertise needs to be integrated more effectively now with the public and governance as demands on agricultural, industrial and resource sectors, all dependant on geology and its resources including its water resources escalate with world population set to double by 2050 .

For example, food chemists test for metal(loids) inherited from geology and anthropocentric processing additions. Natural metal anomalism, or contamination, in food is far more common than appreciated by the public or even health professionals including nutritionist. Under-testing food pollution in all nations frustrates these food chemists to gain geographic and temporal insight $[8,18]$. Such data is urgently required to be integrated with process and chemical engineers, geologists and mapping geoscientist, soil and agricultural scientists if we are to avoid or mitigate toxic metal ingress to food and drinking waters.

This need is highlighted with sobering data; $2.35 \times 10^{12} \mathrm{M}^{2}$ of arable land worldwide is considered contaminated by heavy metals and in China alone $2.786 \times 10^{9} \mathrm{M}^{2}$ of agricultural soils is considered polluted with cadmium (see below). There is nowhere near enough testing of food pollutants and its tracking done to be effective, along with internationally uniform standards, vital also for trading nations to gain social license. Considerations are now being given how to qualify and map such potential Medical Geology impacts globally [8].

There is an urgent need to apply geochemical and mineralogical techniques to pathology and the study of internal metabolic pathways and cell signaling. Both essential and harmful links between Earth materials and human health need to be more fully understood, particularly excesses or deficiencies of elements, ions and key micronutrients such as iodine, iron, zinc, selenium and toxic cadmium, arsenic, and radon. Globally widespread but less well-defined agents such as quartz and other deleterious minerals, such as certain fibrous and phyllosilicate species of the serpentine, amphiboleinosilicates groups need to be highlighted. Members include chrysotile-asbestos, tremolite and vermiculites respectively.

Numerous Medical Geology questions remain, which when resolved amongst confounding factors can illuminate adverse geogenic factors to mitigate or beneficial geogenic factors to promote in health. For example, in BRCA Breast Cancer what metal(loid) milieu if any, impacts metal-enzyme homeostasis and cell signaling escalating disease onset, progression or amelioration and recovery? And if so, what molecular mechanisms and environmental or cultural factors may further treatment and prevention? The current study on cadmium in Breast Cancer is an effort in that direction.

Benefits of metalliferous drugs is a new direction in treating neurological diseases such as psychosis, furthering Alzheimer's research after a decade's long biological plaque paradigm, changing to multifactorial understandings involving metal homeostasis disruptions. Will we see the same directions in cancer research? There are already metalliferous disease treatments such as lithium, platinum and arsenic (hairycelled leukemia). With more pathology metabolic pathway and pharmacology research, we will see more targeted less harmful multifactorial targeting strategies, already underway in neurobiology pharmacology formulations. Geology and its spatial geochemical links to health may also provide insights [8].

Medical Geology is a subject that is not so much emerging as "re-emerging" history of Medical Geology. The relation between rocks, minerals and human health has been known for many millennia by ancient societies aware that metallic and other geological minerals precipitated serious illnesses in certain geographic areas. Mining mercury or arsenical gold ores sickened people from metal exposure so that certain areas were to be avoided as 'sick ground'. Ancient Chinese, Egyptian, Islamic, and Greek texts describe the many therapeutic benefits of various rocks and minerals, as well many health problems. Ancient trade routes in sea salts are legendary and more recently this could also be attributed to deficiencies such as iodine in some thin skeletal soils. Communities in upland areas were once commonly afflicted by iodine deficiency, because iodine is easily leached from thin soils in exposed areas with high rainfall.

More than 2,000 years ago Chinese texts described the use for medical purposes of 46 different minerals. Mineral and metal prospecting, mining and smelting may have been the initial links to these discoveries further back in time, such as the effects of arsenic. Garlic is a sulphur metabolizing plant with similar ability to its water hyacinths relative in taking up metals, including toxic cadmium and arsenic. The later was likely known in China, perhaps as far back as 6,000 years ago. Wild garlic was collected, burned and the ash assayed for physical gold in mineral exploration within arsenical sulphide mineralized ground commonly associated with gold. Gold was extracted from the wild garlic bulb and weighed to assess how likely the ground was economically mineralized [19]. Therefore, a strong connection between gold and arsenic geology and knowledge of herbal healing combined with metals was likely entwined in China thousands of years ago. Certain metals were known to increase the effectives of herbal formulations. It is possible therefore, today's technique of treating certain leukemia's with arsenic was already known in ancient times, as was its use as a stimulant. 
Even in more recent times, and occasionally today the malpractice of race horse doping occurs with potassic arsenic, cadmium, mercury, bismuth or gold or platinum chlorides and iodides occurs. Adulteration of chicken feed pellets with arsenic to reduce pathogens was also common and likely still occurs in some divisions.

The practice of preserving and altering some herbal formulations with arsenic species such as the red colored realgar ( $\alpha$-As4S4) and orange-red orpiment (As2S3) and other metals species may stem from this ancient historical perspective. This is a Medical Geology health concern from our modern understanding of organic methyl and ribose arsenic and directly toxic inorganic arsenic oxide and sulphide species. It is possible the ancients were inadvertently practicing what we are discovering about metal homeostasis today treating certain diseases, such as iron homeostasis in Alzheimer's, or pathology abrogation of some metal toxicities with others. However, this would be very crude. Today it is essential to ensure herbals are free of toxic metals such as cadmium, arsenic, lead, mercury and antimony.

A basic law of toxicology was first proposed by Paracelsus: All substances are poisons; there is none which is not a poison. The right dose differentiates a poison and a remedy". Thus, negative biological effects can result from both increasing and decreasing concentrations of various trace elements. Medical Geology has been practiced for thousands of years, probably since the dawn of time when human species and animals utilized mineralized sediments such as salt licks and clays including bentonite to absorb toxins in the gut, similarly used in agriculture practices. The skeletal exoskeletons of diatoms are utilized to absorb toxins such as bile in the gut and so increase productivity. Where such diatomite deposits occur in Australia (Barraba, NSW). They are commonly used by animals, including Kangaroo. Diatomite absorbent products are used as "kitty litter" and as petrochemical absorbents' and agricultural chemical carriers. Like clays, activated carbon and various organic wastes, diatomite's are a potential "phyto" exclusion agent of heavy metal in polluted soils to prevent their metal ingress to crops and another biota. Bentonite clays are known to deter bacterial promotion specific to metal mobility and acid mine drainage of these pollutants [20,21].

The deliberate eating of soil and clays called Geophagia (also called "geophagy") by animals and humans is considered by many nutritionists to be either a learned habitual response, or as an inbuilt response to nutritional deficiencies resulting from a poor diet. It is known from many ancient and rural societies. It is now the focus of multidisciplinary research including epidemiological studies and risk assessment as supplier of mineral nutrients, such as iron, or potentially harmful elements such as lead, arsenic or radio nuclei.

Historical and more recent medical practitioners utilized ancient geological knowledge extensively to treat disease, noting the effectiveness of some metallic minerals. Bismuth, a curative agent for gastric ulcers (by killing Helicobacter pylori), aspects known to ancients such as Aristotle [22]. This was the clue for researchers (pathologist, Robin Warren and physician, Barry Marshall) in Perth, Western Australia for its "rediscovered" and development as an intestinal cancers preventative. As so often happens with medical paradigm shifts (from spicy food dogma as the cause of ulcers in this case), one of the researches deliberately acquired the condition and cured himself to convince the medical fraternity. However, it still took many years, (and other antibiotics) for this groundbreaking concept to be adopted by clinicians.

Another example is melarsoprol, a toxic mixture of arsenic and polyethylene glycol developed in 1941, still the only treatment available for advanced forms of African sleeping sickness caused by an insect transmitted protozoa parasite. Without it sleeping sickness is fatal. However, this drug, nick named "Arsenic in antifreeze", kills one in 20 patients, scaring veins and causing blood vessels to collapse [23]. Overt surficial vein scaring was observed in NE Victoria, Australia in the Murmungee Basin where domestic water had been siphoned from disused flooded arsenical gold mine stopes nearby [10]. Murmungee Basin is a small part of the Ovens Gold belt, a major food bowl in Victoria within a down faulted graben valley. In the 1980's it was reported to have the highest Breast Cancer incidence in Australia. It was reasoned a possibly associates to this BC incidence may be ground water linked arsenical gold mineralisation, historical arsenic pest control of tobacco and other crops, as well recycled ground waters concentrating metal(oids) in the dry season [10].

With today's recycling focus, remediation research considers ways to recover valuable metals to pay for removing dangerous heavy metal from wastes including mine liquors and this will now extend to industrial and E-wastes in future. The sulfur metabolizing habit of the wild garlic's relative, the water hyacinth, was the clue to one of the most effective in the extraction of dangerous metals from polluted waters with economy by recovering precious metals. As experience in the Californian gold mines in the emerging 1970's gold boom had shown, under optimal hydroponics conditions one hectare of water hyacinth growing in suitably prepared labile metal laden mine waters, can extract dangerous metals, including cobalt and cadmium, and up to $1 \mathrm{~kg}$ gold and $1 \mathrm{~kg}$ silver every two days to pay for the process. These techniques, largely forgotten due to emerging modern remediation strategies of treating AMD from mine wastes need to be reinvestigated.

Moreover, these examples highlight the fact that many plants absorb metal's, including radioactive elements, that easily pass into the food chain, such as through milk and to young children. Indeed, $\mathrm{Cd}$ is quite labile and absorbed in stable foods such as lettuce and rice easily.

Certain plants take this to the extreme. Pennycress was the first 'hyperaccumulating' plant identified in more recent historical times, in 1865. It's 'odd habits' came to light when incinerated ash from plants growing on zinc and cadmiumrich soils near the Belgian-German border was found to be 
$17 \%$ zinc. The foliage of the yellow-flowered crevice-dweller Alyssum bertolonii can contain as much as $1 \%$ nickel (Ni) - two hundred times the level that would kill most plants. As citrate, nickel can be highly concentrated in the sap of a serpentine tree, S'eve Bleue', (Sebertia acuminate), native to New Caledonia, which recorded analyses reaching $25.7 \% \mathrm{Ni}$, turning the sap blue [2]. This was sufficient it seems to have considered mining the metal by logging. Families of plants hyper accumulating Ni include Buxacea, such as boxwoods from Cuba with up to $2.5 \% \mathrm{Ni}$ in Buxus vucciniodes; Euphborbiacea (flowering shrubs), especially Leucocroton from Cuba, (up to $6 \% \mathrm{Ni}$ ), Phyllanthus from New Caledonia (up to $3.6 \% \mathrm{Ni}$; Floacourtiaceae (flowering trees and shrubs) from New Caledonia, especially Homalium and Xylosoma (up to $1.5 \% \mathrm{Ni}$ ) and notably Brassicaceae (herbs and forbs), mostly from southern Europe [2].

Obviously, such hyper accumulation is one of geologicalecological tolerance to nickel and base metal mineralisation. Brassicaceae for example have been considered for phytoremediation, such as Berkheya coddii due to its high biomass being $2 \mathrm{~m}$ tall and able to concentrate $\mathrm{Ni}>2 \% \mathrm{Ni}$. Others include Alyssum with 48 species, especially. A. bertonii accumulating up to $2.9 \% \mathrm{Ni}$ and Thlaspi (Pennycress, with 23 species) with up to $3.15 \% \mathrm{Ni}$.

Modern research now aims to understand how such 'hyperaccumulators' managing metals could help re-vegetate contaminated soils, supplement dietary deficiencies, mop up industrial pollution or even harvest metals from soil $[2,8,24]$.

Cadmium $(\mathrm{Cd})$ as a major contaminant has a wide distribution in soil, plants, water, air and food supplies [17]. Cd, is a naturally occurring metal element existing in earth's crust that is generally complexed with zinc or lead compounds $[18,19,26]$. It is used in many industries and commercial products such as TV screens, batteries, paints, alloys etc [27]. Cd, other heavy metal pollutants, essential minerals and metal(loids) such selenium and zinc are then geogenically remobilized to biota, impacting health through food bowl, water and air quality, both negatively and positively, simultaneously. In nature the economically important Brassicaceae (mustard and cabbage) family of plants are noteworthy bioaccumulators of cadmium, similarly to nickel as noted, and importantly zinc, which also features in the Violacea family. Zinc is taken up by plant roots through active transport. Due to the chemical similarity of toxic cadmium to essential metal zinc which is involved in enzymes, hormone synthesis and DNA replication, there are multiple health issues with cadmium.

\section{Cadmium Pathology}

Considering essential zinc importance's to endocrine function and toxic cadmiums chemical similarity to zinc, one of the major potentially health issues is endocrine disruption by cadmium in human and animal health. Kidney function may be one of those highlighted in this study of Cd links with Breast Cancer.
The discovery of the cadmium (Cd)-binding protein from horse kidney in 1957 stimulated research on this low-molecular weight, cysteine-rich protein called Metallothionein (MT) in Cd toxicology. MT's were found in mammalian tissues revealing their major involvement in the physiology of essential metal homeostasis, such as essential $\mathrm{Zn}, \mathrm{Cu}$. Subsequently this lead to a better understanding of the molecular pathology pathways of acute and chronic $\mathrm{Cd}$ liver and kidney toxicity. Cd-bound to MT is responsible for $\mathrm{Cd}$ accumulation in tissues and the long biological half-life of $\mathrm{Cd}$ in the body.

MT's protect against cytotoxicity of $\mathrm{Cd}$ and other toxic metals, scavenging free radicals generated in oxidative stress. Of the four common Metallothioneins, MT-1 and MT-4 occur in most tissues with some organs expressing sex, strain and stimuli inducible differences. MT-3 mainly occurs in brain and MT-4 is restricted to squamous epithelia. MT's occur mainly in cytoplasm but also in mitochondria, nuclei, liposome's, and exosomes prominent from liver. Liver, the main target of acute toxicity subsequently involves stimulating de nova MT synthesis, that binds $\mathrm{Cd}$, also from other injured organs. This Cd-MT is passed on to the kidney, in turn subject to chronic toxicity. Filtered by the kidney, Cd-MT is then endocytosed, liberating $\mathrm{Cd}$ by degraded lysosomes in the proximal tubules that may then degrade the kidney cells structure and function. The resulting proteinuria, and Cd-MT in urine is the biomarker of tubular injury.

It has been shown from liver-derived exosome-laden lncRNA Metallothionein 1D pseudogene (MT1DP) aggravates $\mathrm{Cd}$ induced nephrotoxicity. MT1DP had previously been identified to promoted Cd-induced hepatocyte damage, and as an intermediate to Cd-induced nephrotoxicity. A Chinese study of 100 participants showed blood MT1DP levels correlated with urine $\mathrm{Cd}$ content and the extent of nephrotoxicity. MT1DP, induced mainly by hepatocytes, is packaged into extracellular exosomes, circulated, delivering MT1DP targeting to kidney cells, worsening Cd-induced nephrotoxicity, evidenced in both Cd-poisoned individuals and in vitro cells. Moreover, MT1DP was found to reinforce $\mathrm{Cd}$-induced toxicity in kidney cells by indirectly breaking the equilibrium between the pro-apoptotic and anti-apoptotic effects conducted by BAX and Bcl-xL, respectively [28].

The biological half-time of cadmium in the human kidney is considered to be very long: 10-15 years, explaining the life-long accumulation of cadmium. In excessively exposed individuals toxic concentration are considered to be around 200 $\mathrm{ug} / \mathrm{g} \mathrm{Cd}$ [5]. This study focuses on Urine $\mathrm{Cd}$ as the biomarker of cadmium toxicity with Breast Cancer presentation.

Despite this long kidney half-life of $\mathrm{Cd}$, one may suggest future study match such results from potential environmental perspectives relating to $\mathrm{BC}$ presentation with a multi element nail clipping analyses, including pre diagnosis analyses to broaden time frames of toxic metal exposures. This may better discriminate environmental survey factor and potential ameliorating metal(loid) exposures. 
It is interesting that Cd-induced toxicity in kidney cells indirectly break the equilibrium between the pro-apoptotic and anti-apoptotic effects conducted by BAX and Bcl-xL, respectively. As this regulation may therefore also be involved not only in Kidney damage but BC and link metal homeostasis deregulation by metal toxicants and amelioration by essential metal(loids) and potentially others as well, such as nickel in combination with selenium.

In terms of food chain $\mathrm{Cd}$, an interesting experiment on lettuce, which is subjected to easy Cd uptake, found salicylic acid seed priming increased resistance of lettuce to $\mathrm{Cd}$ toxicity with increase in germination rate, fresh mass and water content [29, 6]. The mechanism is unknown. One wonders if salicylic acids are a plant adaptation to reduce metal toxicities and uptake, in addition to resist infection.

Salicylic acids are a plants antibiotic, the reason unsprayed vegetables subject to infection have higher salicylic acid content, oft quoted as one reason they are superior to pest sprayed vegetables. This is due to Salicylic acids having antiinflammatory COX inhibitor properties and reducing some cancer risks in humans. It is therefore worthy of following up to see if this extends to ameliorating $\mathrm{Cd}$ toxicity and teragenic impacts in humans, and if the molecular mechanisms involved in abrogating $\mathrm{Cd}$ toxicity, are anti-inflammatory mediated and or more directly involved. In plants and humans it will be interesting if the mechanisms extend to reductions in $\mathrm{Cd}$ uptake as well. The influence of salicylic acid on Cd-MT1DP unpacking from exosomes in kidneys and mitigating BAX and $\mathrm{Bcl}-\mathrm{xL}$ equilibrium disruption by $\mathrm{Cd}$ should be explored along with any notable abrogation of $\mathrm{BC}$ and other cancers, including liver and kidney cancers, as a result of metal(loid) links.

\section{Cadmium Ingress from Geology and Soils to Biota}

In addition to active zinc linkage of cadmium uptake in plants, $\mathrm{Ca}$ and $\mathrm{Fe}$ active uptake is involved, as well as a shared receptor entry route with $\mathrm{Fe}$ and $\mathrm{Mn}[30,31]$. There have been efforts at genetic engineering to limit this uptake in rice, amongst physiochemical efforts at limiting uptake considering rice is a stable food in central and east Asia and of major concern due to cadmiums mobile uptake and high toxicity. Approximately $2.35 \times 10^{12} \mathrm{M}^{2}$ of arable land worldwide are considered contaminated by heavy metals [30-34]. In China, about $2.786 \times 10^{9} \mathrm{M}^{2}$ of agricultural soils are considered polluted with cadmium [35]. This is a staggering degree of potential cadmium and other heavy metal pollution. Spatual distribution and temporal studies in terms of geology and anthropogenic inputs of heavy metals including cadmium in rice and other crops is therefore a critical Medical Geology concern.

Water management growing rice is important since this controls soil Eh which impacts cadmium mobility [36]. In newly flooded soils microbes respire by utilizing oxidized soil components such as $\mathrm{NO}_{3}^{-}, \mathrm{SO}_{4}^{-2}, \mathrm{Mn}^{(3+/ 6+)}, \mathrm{Fe}^{3+}$ and labile dissociated organic matter components that attract electrons during reduction, generating $\mathrm{NO}_{2}^{-}, \mathrm{S}^{2-}, \mathrm{Mn}^{2+}, \mathrm{Fe}^{2+}$ with organic acids of low molecular weight, accompanied by decreasing redox potential [37]. This decreases $\mathrm{Cd}$ solubility due to enhanced $\mathrm{Cd}$ adsorption by iron and manganese oxyhydroxides along with $\mathrm{CdS}$ precipitation [38]. Conversely in drying fields oxidative soil has increased $\mathrm{Eh}$ in which case cadmium forms water-soluble cadmium sulphate $\left(\mathrm{CdSO}_{4}\right)$, resulting in effective uptake of $\mathrm{Cd}$ by rice [39].

In general, however, in alkaline conditions, zinc uptake is low to very low whilst cadmium uptake is medium. Soil remediation needs to be mindful of this disparity, where normally in slightly acidic conditions zinc uptake is high to medium and cadmium remains medium. Differential phyto exclusion agents added to soils should be considered in cadmium polluted regions retarding $\mathrm{Cd}$ ingress whilst promoting zinc ingress to crops. This might be food wastes such as chemically activated nut shell wastes $[18,20]$. General immobilization factors for zinc are Fe$\mathrm{Mn}$, organic matter and calcium, and that for $\mathrm{Cd}$ are calcium, carbon and reducing conditions as mentioned [29]. Unlike zinc, cadmium, not being an essential metal, biogeochemically tends to reflect zinc spatially geochemically in soil, better than zinc itself in surveys. Zinc, essential for carbohydrate and protein synthesis, therefore biogeochemically reflects more the health of plants rather than soil zinc content, more accurately reflected by cadmium, biogeochemical. Substantial changes to plant zinc are needed to reflect soil zinc contents more accurately. Conversely low biogeochemical zinc would then reflect seriously low zinc rock geochemistry (zinc is normally distally dispersive), low biological uptake or blockages in soil zinc mobility (geogenic immobilization), with serious consequences to health.

For instance, low zinc in herbaceous stream roots have been positively associated with regional Type 1 diabetes in Sweden [40]. Trees that contain cadmium due to the ubiquitous geochemical affinity of cadmium with zinc are birch, willow and lesser with poplar. Timber milling industries should be aware of this association potentially handling toxic cadmium and their products. Tree cellulose for example is considered for carbon fiber manufacturing. The practice of cultivating mushrooms (known metal bioaccumulators), in logs also comes to mind.

The Brassicaceae commonly hyperaccumulate $\mathrm{Cd}$ with zinc as mentioned, but the spatual distribution of various hyper accumulating vegetation will reflect geology and tends to be highly elevated locally. The mountain herb Biscutella lavigata for instance, grows mainly in eastern Europe and can contain upwards of $200 \mathrm{ppm} \mathrm{Cd}$ and an order higher magnitude $\mathrm{Cd}$ in roots [41]. What minimal levels to be considered toxic yet more widespread will depend on more active hyper accumulations of cadmium against geochemical gradients from less mineralized geology, albeit $\mathrm{Cd}$ being non-essential (or is it?). Plants perhaps extract toxic cadmium and other metals in the root zone to deal with them in other ways. Cadmium follows zinc closely in hypogene metal deposits, generally quantitatively contained in sphalerite, zinc bearing sulphosalts, particularly tetrahedrite and tennantite. Apart from primary volcanogenic and stratiform massive lead-zinc mineralization's, cadmium is also associated with gold, copper, molybdenum mineralization due to its general association with hydrothermal veining and 
volcanism. The galena and chalcopyrite of these deposit may contain upward of 500ppm Cd. It is noteworthy $\mathrm{Cd}$ in these hydrothermal deposits is invariably more distal to the primary gold, copper and molybdenum metals, therefore covering a wider area.Sedimentary fluvial rocks that have become cemented with manganese and iron can contain significant cobalt originating from ground waters along with significant cadmium (e.g. Bungonia, NSW, Australia). Major stratiform zinc-lead-barium deposits can be a major source of $\mathrm{Cd}$ and in this case natural and mine dispersion into ground waters and aeolian redistribution from tailings and mine wastes can widely distribute heavy metal pollutants and essential metal(loids) such as selenium and zinc simultaneously [8]. In such deposits meteoric waters precipitate hawleyite-greenockite $(\beta-\alpha \mathrm{CdS})$ in ground waters below supergene zinc and lead mineral including smithsonite, anglesite, beudanite, bindheimite and pyromorphite. Where these minerals occur cadmium will be significantly enriched. Here, and in oxidized gossans of gold deposits alike, cadmium will migrate away in the oxidized meteroic waters.

Mushrooms are known accumulators of many metals and picked over geological regions of rocks with geochemically elevated heavy metal above average low contents and then bio-accumulated may still pose serious risks long term. For mushrooms this will be acute in zones of overt mineralisation, that can also be a source of high toxic cadmium, and metalloids such as arsenic when eaten. The average content of cadmium in plants is $0.05 \mathrm{ppm} \mathrm{Cd}$. But in mushrooms the average $\mathrm{Cd}$ content can be $300 \mathrm{ppm} \mathrm{Cd}$ in some species, such as Amanita death cap mushrooms, and peak at exceptionally high values in others. Fungi preferentially scavenge some heavy metals and experimental data shows this can be extremely high [42, 43]. Rhizopus arrhizus can concentrate $3 \% \mathrm{Cd}$ (also $5.4 \%$ $\mathrm{Ag}, 3.1 \% \mathrm{Cr}, 1.6 \% \mathrm{Cu}, 5.8 \% \mathrm{Hg}, 10.4 \% \mathrm{~Pb}$ and $2 \% \mathrm{Zn}$ ) [44]. Indeed, yeast extracts were initially proposed by Russian metallurgists to extract gold from highly refractory arsenical ores. Others fungi are capable of concentrating gold externally, organic gold being toxic, and are implicated in gold nugget formation, as are bacteria and archaea.

It is interesting to speculate if this is a feature of primitive life forms, perhaps as a link to the origin of life through metalenzymatic catalysts at a time when hydrothermal metal "smokers" were common sea floor vents with volcanic activity. Indeed, this ability extends in bacteria to absolute extreme: Zooglia ramigera, may concentrate $40 \% \mathrm{Cd}$ and $40 \% \mathrm{Cu}$; Zooglia sp 25\% Co, $13 \% \mathrm{Ni}$; Thiobacillus ferrooxidans (also utilized with sulfolobus in Biox gold recovery metallurgy) with 35\% Ag, and Micrococcus lutus 35\% $\mathrm{Pb}$ [43].

Similarly, algae are capable of absorbing significant metal. They have also been proposed in waste water phytoremediation of cadmium and antimony. As a food then, macro algae need to be assessed for heavy metals carefully, which will reflect benthic and continental margin geology as well as industrial effluents.
Altogether, this has far-reaching consequences for Medical Geology in wide fields ranging from geomicrobiology to macro biology. Geomicrobiology may bring about wide scale metal toxicity via geogenic remobilization and concentration accumulating in the food chain. Microbial filter feeders such as oysters and crabs are therefore of particular concern for concentrating heavy metals. Cadmium and other metals contaminate vast regions of Western Australia oyster beds for example. The source of these metals is iron containing coastal sedimentary geology. Drinking and irrigation ground waters sourced from wells potentiated by fertilizer stimulated microorganism are another concern, along with recycling grey water accumulation of metals and reapplied to irrigation crops.

Macro algae and fungi consumption from certain geological areas is a particular Medical Geology concern with cultural links. Eating mushrooms is very popular in Europe, but can therefore be problematic. For instance, in Freiburg, German a widespread volcanic hydrothermal mineralization belt of $30 \mathrm{~km}$ strike length with gold mineralization, popular mushrooms picking is cited as one reason to prevent gold mining. These communities of mushroom pickers are at risk of ingesting toxic heavy metals, including arsenic and cadmium. In one sense it would be better to mine the area, since stopping people from eating the mushrooms seems impossible as authorities have not caught up with the risks or are politically reluctant to stop this 'cultural sport'. Globally, Medical Geology has a long way to catch up on geologically mapping areas of health concerns.

\section{Patients and Methods}

\section{Study Population}

Current research is a population-based cross sectional study initiated in the central zones of Shiraz, Fasa, Abadeh, Jahrom and Marvdasht (all patients have been coming to hospitals located in Shiraz, the capital of Fars Province) with the aim of comparing the effect of diet, smoking habits and lifestyle on the incidence of Breast Cancers (stages I to III Breast Cancer usually includes surgery; as Stage III is divided into subcategories known as IIIA, IIIB, and IIIC.) in a total study population of 150 Breast Cancer patients participated along with 37 women in the control group at the same time, aged 20 to 69 years, with incident invasive Breast Cancer identified. This is a descriptive-analytic and a cross-sectional study performed from 1 March 2018 to 1 March 2019. The study population consisted of six hospitals affiliated to Shiraz University of Medical Sciences and all hospitals were teaching hospitals.

At enrolment, each participant completed a self-administered, interview-checked for a 187 item semi-quantitative/qualitative food frequency questionnaire and a questionnaire covering lifestyle habits including information on present and previous smoking, physical activity, reproductive history, health status and weight factors. In total 187 persons filled in the detailed dietary questionnaires. The patients were enrolled in the study when they received their first visit by an oncologist in the University hospitals of Shiraz according to diagnosis criteria. 
Controls were enrolled from the volunteers who lived around the same hospital and referred to the laboratories around for routine annual check-up.

\section{Data Collection}

Face-to-face interviews based on structured and food frequency questionnaires were utilized to obtain demographic lifestyle and dietary information by trained staff at the time of study enrolment. General characteristics including age, weight, height, women body mass index (BMI), education levels, family history of Breast Cancers, history of other cancers in family, Marital status, reproductive history (including use of menopausal hormone therapy for 3 months or longer (estrogen or estrogen plus progesterone; pills or patches), occupational status, second hand or active smoke (>30 min/day), physical activity, living and working address (urban or rural areas), dietary habits, occupational exposure to $\mathrm{Cd}$, exposure to household chemicals, using plastics dishes or plastic water bottles, using home water purifier, postmenopausal hormone use, using $\mathrm{Cd}$ containing cosmetics (lipsticks and eye shadow) and having "Tattoo" were asked from the volunteers and recorded in their structured questionnaires. The heights and weights of volunteers were measured at the time of study enrolment.

The participation proportions; the percentage of participants eligible to participate in the population-based Breast Cancer parent study, who completed the interview was $76 \%$ for case participants and $84 \%$ for control participants. Of those who completed the interview and agreed to participate in the metal sub-study, a participation proportion of $89 \%$ was achieved for urine specimen returns for both case and control participants. University of Shiraz, Educational hospital subjects Committee approved this study. Oral consent was obtained for the interview, and written informed consent was obtained for the urine specimen collection.

Sample Preparation: Spot urine samples were collected from most of participants from 1st March of 2018 to 1st March of 2019 after face to face interviews. Women with missing information on adjustment variable(s) were included in the analysis in a separate category for adjustment. No single variable had data missing for more than $8 \%$ of participants. In sensitivity analyses, the analyses were repeated including only women with complete information on all variables.

\section{Urinary Cd Determination by ICP-MS}

Urinary $\mathrm{Cd}$ concentrations were determined using sector field inductively coupled plasma mass spectrometry on a ThermoFinnigan Element 2 mass spectrometer (Thermo Scientific, Waltham, Massachusetts), following procedures similar to the international Protocols [44]. Urine samples were diluted $1+$ $5: 6$ and $1+9$ with $2 \%(\mathrm{v} / \mathrm{v})$ high-purity of Nitric acid (225711, Sigma-Aldrich; $70 \%$, purified by redistillation, $\geq 99.999 \%$ trace metals basis); containing 5 internal standards for analysis. The formation of the isobaric interference molybdenum oxide was monitored throughout the analytical sequence, and where appropriate, a run position empirical correction was applied to the $\mathrm{Cd}$. Molybdenum oxide formation was also evaluated with stable molybdenum isotope spikes in selected participant samples. Molybdenum oxide formation fractions were in the range $0.0015-0.0025$, and molybdenum oxide correction at the median urinary $\mathrm{Cd}$ concentration was $20 \%$, consistent with published results from other populations.

\section{Statistical Analysis}

Multivariate logistic regression models were used to assess the effects of urinary $\mathrm{Cd}$ levels on Breast Cancer risk, controlling for age and for suspected or established risk factors (age, weight, height, BMI, education levels, family history of Breast Cancers, history of other cancers in family, marital status, reproductive history, occupational status, second hand or active smoke(> $30 \mathrm{~min} /$ day), physical activity, living and working address (urban or rural areas), dietary habits, occupational or household exposure to $\mathrm{Cd}$, postmenopausal hormone use, using $\mathrm{Cd}$ containing cosmetics (lipsticks and eye shadow) and having "Tattoo".

\section{Results and Discussion}

Finally, an investigation to examine whether the disease process per se or treatment may have altered Cd levels in analyses stratified by disease stage (localized versus regional/ distant) and by treatment (surgery and/or radiation only versus chemotherapy and/or hormonal therapy) was completed. Similar associations between $\mathrm{Cd}$ levels and Breast Cancer risk were observed among participants with localized Breast Cancer Odds Ratio (OR): $(\mathrm{OR}=1.35 ; 94 \% \mathrm{CI}: 1.2-1.8 ; \mathrm{p}=0.004)$ and participants with regional/distant Breast Cancer $(\mathrm{OR}=1.81$; $96 \%$ CI: 1.4-2.4; $\mathrm{p}=0.001)$ compared to controls.

The association of Breast Cancer risk with $\mathrm{Cd}$ levels did not differ between participants treated by surgery and/or radiation $(\mathrm{p} \geq 0.05)$ only (OR=1.34; 93\% CI: 1.0-1.5) and those treated with chemotherapy (OR=1.35; 94\% CI: 1.0-1.6), eliminating those factors.

\section{Diet and lifestyle factors $(\mathrm{n}=150)$}

As we showed in Tables 1 and 2 , no practical difference was found between cases and control regarding living or working in urban areas with, dietary habits and food Cd resources in Iranian daily regimen including rice, bread, dairies, Black tea, Coffee, crops in recent ( 3 years) and past ( $>20$ years) smoking habits, smoking cessation, exposure to household chemicals, consuming $\mathrm{Cd}$ as household substances such as plastic dishes and bottles and using water purification devices at home or consuming $\mathrm{Cd}$ as Cosmetic substances such as eye shadows. In the current study all above parameters in subgroups compared among different residential cities with the Capital city or other less populated towns, with results showed the following differences: Ours studies shows that women with dietary habits of Indian rice consummation had a non-significance 
result $\mathrm{p}=0.005$. We confirm the same statistical results in individual study about dietary habits of bread, black tea and coffee consummation. Also, we can show that a Breast Cancer condition is not associated with Academic Education and Employed status in this study. Finally, "Tattoo selection" and colorful cosmetics, incidence is not associate with age: Women older than 40 years had the same statistical results than the younger group in the range of 20 to 40 years old.

\begin{tabular}{|l|l|l|}
\hline Characteristics & $\begin{array}{l}\text { Women } \\
(\mathrm{n}=78)\end{array}$ & $p$-Value \\
\hline Age (mean \pm SD) & $38.21+2.24$ & 0.178 \\
\hline $\begin{array}{l}\text { Body Mass Index (BMI) } \\
\text { (mean } \pm \text { SD) }\end{array}$ & $26.81+2.3$ & 0.137 \\
\hline Drinking Herbal Tea (yes) & 33 & $0.003^{* * *}$ \\
\hline Academic Education (yes) & 42 & $<0.001^{* * *}$ \\
\hline Employed (yes) & 31 & $<0.001^{* * *}$ \\
\hline $\begin{array}{l}\text { History of Cardiovascular } \\
\text { (yes) }\end{array}$ & 11 & 0.232 \\
\hline $\begin{array}{l}\text { History of Cancer in family } \\
\text { (yes) }\end{array}$ & 65 & $0.028^{* *}$ \\
\hline History of Breast Cancer (yes) & 31 & $0.031^{* *}$ \\
\hline Active Smoking(yes) & 27 & $0.031^{* * *}$ \\
\hline $\begin{array}{l}\text { Tattoo or colorful cosmetics } \\
\text { (yes) }\end{array}$ & 53 & $<\mathbf{0 . 0 0 1 * * *}$ \\
\hline $\begin{array}{l}\text { Plastics dishes at home/ } \\
\text { work + Routine exposure to } \\
\text { household chemicals (yes) }\end{array}$ & 34 & 0.218 \\
\hline Water purifier at home (yes) & 18 & 0.514 \\
\hline Plastic bottles & 36 & 0.561 \\
\hline $\begin{array}{l}\text { Routine consumption of } \\
\text { Green vegetables (no) }\end{array}$ & 16 & 0.845 \\
\hline Indian Rice (yes) & $48 * *$ \\
\hline Fast Food (never) & 9 & 0.514 \\
\hline
\end{tabular}

Table 1 : Age dependent demographic factors, background diseases and lifestyle in Range of 20 to 40-year-old residents of Fars Province.

\section{Urine Cadmium Levels (U-Cd)}

In a common, multivariable-adjusted model (adjusted for all age group, smoking, daily regimen and menopausal status), urinary $\mathrm{Cd}$ Levels in all Breast Cancer patients and control groups who used to drink herbal teas (more than 3 times in a week) were significantly ( $p=0.003$ ) lower than others.

Tables 1 and 2 show the mean of U-Cd levels in Breast Cancer patients and those in the control group in the range of 20 to 40 and over 40 years of age respectively. The mean concentration of cadmium in the urine of Stage III patients was significantly much higher than the control group $(0.1092 \pm 0.0046 \mathrm{mg} / \mathrm{L}$ vs. $0.0342 \pm 0.0011 \mathrm{mg} / \mathrm{L}, \mathrm{p}=0.001)$. It might be described as an association between U-Cd and anthropometric factors, that is considered in specified analyses. Urine Cd levels in smokers:
Although we found significant difference between the mean U-Cd levels of recent active or passive smokers $(0.0607 \mathrm{mg} / \mathrm{L}$ $\pm 0.0211, \mathrm{n}=28)$ and non-smokers $(0.0222 \pm 0.0054, \mathrm{n}=48)$, $\mathrm{p}=0.031$.

Urine Cd levels in Menopausal Hormone Therapy: Long term use of menopausal hormone therapy for 3 months or longer (estrogen or estrogen plus progesterone; pills or patches caused increased $\mathrm{U}-\mathrm{Cd}$ level $(\mathrm{p}=0.011)$ in the total population of cases and control.

\section{Urine Cadmium levels (U-Cd)}

The results were selected confounders on the basis of knowledge about risk factors for Breast Cancer and sources of cadmium exposure. Results from multivariable models were stratified by age at enrollment (20-29, 30-39, 40-49, 50-59 or 59-69 years) and finalized studies as two groups of 20 to 40 years (Table 1) and over 40 (in Table 2). The pattern of all patient groups, the history of cancer in family and especially Breast Cancer had significantly been observed while the statistics shows patients in the age of 40 probably are at higher risk $(p=0.022)$ in comparison to the younger group $(p=0.028)$.

The results of current studies revealed that chronic exposure to $\mathrm{Cd}$ probably related to the association between $\mathrm{Cd}$ and renal diseases, cardiovascular outcomes, cancer especially Breast Cancer history in the family, Tattoo or colorful cosmetics, eating Indian rice in dietary habits (due to expensive local rice costs) [7].

\begin{tabular}{|c|c|c|}
\hline Characteristics & Women $(n=72)$ & $p$-Value \\
\hline Age $($ mean $\pm \mathrm{SD})$ & $46.53 \pm 3.67$ & 0.065 \\
\hline $\begin{array}{l}\text { Body Mass Index }(\mathrm{BMI}) \\
(\text { mean } \pm \mathrm{SD})\end{array}$ & $27.01 \pm 1.38$ & 0.253 \\
\hline Drinking Herbal Tea (yes) & 51 & $0.003 * * *$ \\
\hline Academic Education(yes) & 26 & 0.052 \\
\hline Employed (yes) & 15 & $<0.001 * * *$ \\
\hline $\begin{array}{l}\text { History of Cardiovascular } \\
\text { (yes) }\end{array}$ & 39 & 0.198 \\
\hline $\begin{array}{l}\text { History of Cancer in family } \\
\text { (yes) }\end{array}$ & 50 & $0.022 * *$ \\
\hline $\begin{array}{l}\text { History of Breast } \\
\text { Cancer(yes) }\end{array}$ & 37 & $0.027^{* *}$ \\
\hline Active Smoking(yes) & 9 & 0.331 \\
\hline $\begin{array}{l}\text { Tattoo or colorful cosmetics } \\
\text { (yes) }\end{array}$ & 18 & $<0.001 * * *$ \\
\hline $\begin{array}{l}\text { Plastics dishes at home/ } \\
\text { work + Routine exposure to } \\
\text { household chemicals (yes) }\end{array}$ & 24 & 0.333 \\
\hline Water purifier at home(yes) & 7 & 0.809 \\
\hline Plastic bottles & 27 & 0.615 \\
\hline $\begin{array}{l}\text { Routine consumption of } \\
\text { Green vegetables (no) }\end{array}$ & 39 & 0.801 \\
\hline
\end{tabular}




\begin{tabular}{|l|l|l|}
\hline Indian Rice (yes) & 51 & $0.003 * * *$ \\
\hline Fast Food (never) & 24 & 0.506 \\
\hline
\end{tabular}

Table 2 : Age dependent demographic factors, background diseases and lifestyle in over 40 years' old residents of Fars Province

For future programs, it is recommended to compare multielement nail and hair analyses for heavy metal(loids) such as arsenic and ameliorating metalloids such as essential selenium and zinc [45]. They may represent better nuance of pollutants cumulatively over time and pick up environmental factors not seen discriminated amongst some individuals in lifestyle surveys, or indeed mitigating factors such as selenium. Spanish subjects for example who had higher selenium or selenium plus nickel in nail analyses when polluted with cadmium, arsenic and lead had low cancer rates compared to those with polluting metals alone [46]. Pre-diagnosis nail analyses over time frames would also be illuminating. This may match environment and against genetic profiles e.g. with BRCA protein and miRNA vaccine $[15,47-49]$.

\section{Conclusions and Recommendations}

Urinary Cd level in Breast Cancer patients in Stage III was 3 times higher than control. Long term using of menopausal hormone therapy for 3 months or longer (estrogen or estrogen plus progesterone; pills or patches caused increased U-Cd level $(\mathrm{p}=0.011)$ in total population of cases and control.

This is the first study on U-Cd in Iranian population in all Breast Cancer patients in all stages I to III Breast Cancer that usually includes surgery; as Stage III is divided into subcategories known as IIIA, IIIB, and IIIC and females using Cd containing cosmetics (lipsticks and eye shadow) and having Tattoo didn't show higher U-Cd despite similar studies in western countries.

Urinary Cd Levels in total population of cases and control who used to drink herbal teas (more than 3 times in a week, despite of age) were significantly ( $\mathrm{p}=0.003)$ lower than others. Higher U-Cd levels in the diagnosed Breast Cancer could be considered as a new etiologic biomarker without association with recent lifestyle, diet and smoking habits.

The results of current studies revealed that Chronic exposure to $\mathrm{Cd}$ may relate to the association between $\mathrm{Cd}$ and renal diseases, cardiovascular outcomes, cancer especially Breast Cancer history in the family, Tattoo or colorful cosmetics, eating Indian rice in dietary habits (due to expensive local rice costs).

We recommend women older than 40 years, particularly with family breast cancer history, to largely avail themselves of a plant based diet, along with adequate heavy metal ameliorating trace elements e.g. selenium, to drink anti-inflammatory herbal tea, certainly in place of anti-inflammatory medicines, a known contributor of Breast Cancer in consuming cultures and nonsmoking habits.
Considering essential zinc importance's to endocrine function and toxic cadmiums chemical similarity to zinc, one of the major potentially health issues is endocrine disruption by cadmium in human and animal health. Kidney function may be one of those highlighted in this study of cadmium in Breast Cancer, as well abrogating essential elements.

Salicylic acids should be investigated in humans as recommended in the discussion section in relation to potential abrogation of $\mathrm{Cd}$ toxicity and carcinogenesis in Breast Cancer and other cancers. Cd-induced toxicity in kidney cells indirectly breaking the equilibrium between the pro-apoptotic and anti-apoptotic effects conducted by BAX and Bcl-xL, respectively. As this regulation impacts Kidney damage and $\mathrm{BC}$, link to metal homeostasis deregulation by metal toxicants and amelioration by essential metal(loids) such as nickel in combination with selenium.

In future programs it is recommended to compare multielement nail and hair analyses for heavy metals and ameliorating metalloids such as essential selenium and zinc. They may represent better nuance of pollutants cumulatively over time and pick up environmental factors not seen discriminated amongst some individuals in lifestyle surveys, or indeed mitigating factors such as selenium. Spanish subjects for example who had higher selenium or selenium plus nickel in nail analyses when polluted with cadmium, arsenic and lead had low cancer rates compared to those with polluting metals alone. Pre-diagnosis nail analyses over time frames would also be illuminating to match environment and against genetic profiles e.g. with BRCA. This study did not target mining communities specifically. Considering the results in Spain related to metals, such communities should be included in future cancer studies.

Approximately $2.35 \times 10^{12} \mathrm{M}^{2}$ of arable land worldwide are considered contaminated by heavy metals and in China, alone some $2.786 \times 10^{9} \mathrm{M}^{2}$ of agricultural soils were considered polluted with $\mathrm{Cd}$. This is a staggering degree of potential cadmium and other heavy metal pollution. This data indicates spatial distribution mapping and temporal studies in terms of geology and anthropogenic inputs of heavy metals to rice and other crops linked to health impacts is of critical Medical Geology concern. Such regions are recommended to be mapped in Medical Geology terms with geogenic health 'indices'. 
Acknowledgments

Thanks to:

Prof. Dr. Olle Selinus,

Prof. Dr. Robert Finkelman

Prof. Dr. Jose A. Centeno

Pioneers of Medical Geology, they are always... ours Teachers

Especially, we are very thankful to the medical team and staff of Shiraz Educational Hospitals for technical support of this study and also to the Nutrition and Food Sciences Research Center, Islamic Azad University, Tehran Medical Sciences, Islamic Azad University, Tehran, Iran.

\section{References}

1. Ziarati P, Makki FM, Vambol S, Vambol V (2019) "Determination of Toxic Metals Content in Iranian and Italian Flavoured Olive Oil". Acta Technologica Agriculturae 2: 64-69.

2. Colin E Dunn (2007) "Handbook of Exploration and Environmental Geochemistry". Biogeochemistry in Mineral Exploration, Elsevier 9.

3. Mandon CL (2017) "Volatile transport of metals in the andesitic magmatic-hydrothermal system of White Island". Victoria University of Wellington,

4. Byrne C, Divekar SD, Storchan GB, Parodi A, Martin MB (2009) "Cadmium - a metallohormone?" Toxicol Appl Pharmacol 238: 266-271.

5. Nordberg GF, Fowler BA, Nordberg M, Friberg L (2007) "Handbook on the Toxicology of Metals". 3rd Edition. Academic Press, New York 2007: 445-486.

6. Zorrig W, El Khouni A, Ghnaya T, Davidian JC, Abdelly C, et al. (2013) "Lettuce (Lactuca sativa): a species with a high capacity for cadmium $(\mathrm{Cd})$ accumulation and growth stimulation in the presence of low Cd concentrations". J Hortic Sci Biotechnol 88: 783-789.

7. Ziarati P, Moslehisahd M (2017) "Determination of Heavy Metals $(\mathrm{Cd}, \mathrm{Pb}, \mathrm{Ni})$ in Iranian and Imported Rice Consumed in Tehran". Iranian Journal of Nutrition Sciences \& Food Technology 12: 97-104.

8. Hochwimmer B, Ziarati P, Selinus O, Elwej A, CruzRodriguez LD, et al. (2020) “A Predictive Geological Tool of Type 3 Diabetes (Alzheimer's Disease): The Polygonal Vortex Mineralisation Model a Medical Geology Perspective". J of Diabetes \& Endocrinology 2.

9. Hochwimmer B (2004) "Internal reports on Dart Exploration License; Minerals and Petroleum Department of Primary Industry". Victoria, Australia 13: 13.

10. Hochwimmer B, Cruz-Rodríguez L (2005) "The Polygonal Vortex Mineralisation Model: A Predective tool of health indices and the proposed indices: As a subdiscipline of Medical Geology". VI Congreso de Geologia”: Geología - Geoquímica médica.

11. Selinus O, Alloway B, Centeno JA, Finkelman RB, Fuge R, et al. (2005) "Essentials of Medical Geology". Elsevier, Amsterdam 2005: 820.
12. Pielichowska M, Wierzbicka M (2004) "Uptake and localization of cadmium by Biscutella aveggata, a cadmium hyperaccumulator", Acta Biologica Cracoviensia 46: 5763.

13. Jafre'e T, RR Brooks, J Lee RD (1976) "Reeves Sebertia Accumina, nickel accumulating plants of New Caledonia" 1976.

14. Katie M O'Brien, Alexandra J White, Brian P Jackson, Margaret R Karagas, Dale P Sandler, et al. (2019) "Toenail-Based Metal Concentrations and Young-Onset Breast Cancer". Am J Epidemiol 188: 34-43.

15. Lambert Brown D, Hochwimmer B, Selinus O, Zayas Tamayo AM, Cruz-Rodriguez L (2020) “A RNA-peptide fusion as a vaccine candidate against the novel corona virus (COVID-19)". Journal of Diabetes and Endocrinology Research 2.

16. Liu HJ, Zhang JL, Christie P, Zhang FS (2008) "Influence of iron". 2015a.

17. Hadiani MR, Dezfooli-manesh S, Shoeibi S, Ziarati P, Mousavi Khaneghah A (2014) "Trace elements and heavy metals in mineral and bottled drinking waters on the Iranian market. Food Additives \& Contaminants: Part B: Surveillance" 8: 18-24.

18. Ziarati P, Mostafidi M, Shirkhan F, Tamaskoni-Zahedi (2018) "Analysis ANALYSIS of removal Methos of toxic heavy metal using bio-absorbs. Technogenic and ecological safety" 4: 62-76.

19. Boyle RW (1979) "The geochemistry of gold and its deposits, Canada Geological Survey Bulletin” 280: 1979.

20. Jallilian Z, Ziarati P (2016) "High potential of Ferulago Angulate (Schecht) Boiss in Adsorption of Heavy Metals". Biomed Pharmacol J 9: 201-208

21. Keith D Morrison, Stanley N Williams, Lynda B Williams (2017) "The Anatomy of an Antibacterial Clay Deposit" (2017): A New Economic Geology. Bulletin of the society of economic geologists 112: 7 .

22. Emilia G, Longo G, Luppi M, Gandini G, Morselli M, et al. (2001) "Helicobacter pylori eradication can induce platelet recovery in idiopathic Thrombocytopenic Purpura". Blood 97: 812-814.

23. Hollingham R (2005) "Article on neglected tropical diseases". New Scientist. Journal of Advances Médicos de Cuba; Año X No 51: 33.

24. Cruz-Rodriguez L, Hochwimmer B, Selinus O (2005) "Medical Geology in Cuba". GEO 2005: 10-17.

25. Ziarati P (2012) "Contamination of Cadmium and Lead in Iranian Jujube. "Assays on Environmental Studies". ATINER 2012: 21-29.

26. Ziarati P, Behbahani P, Karbalaie-Mohammad N (2012) "Role of Unprofessional Storage methods on the heavy metal content of Rosa Damascena (Gole Mohammadi)". Journal of Pharmaceutical and Health Sciences 1: 73-78.

27. Ziarati P, Farasati Far B, Mashayekhi E, Sawicka B (2019a) "Removing arsenic by food-processing waste (Zizyphus jujuba seeds) and study on its adsorptive properties". Technogenic and ecological safety 5: 62-70.

28. Gao M, Dong Z, Sun J, Liu W, Xu M, et al. (2020) Liverderived Exosome-Laden IncRNA MT1DP Aggravates 
Cadmium-Induced Nephrotoxicity. Environ Pollut. 258: 113717.

29. Melisa Šabanović, Adisa Parić, Mirela Briga, Erna Karalija1 (2018) "Effect of salicylic acid seed priming on resistance to high levels of cadmium in lettuce" (Lactuca sativa L.) Genetics \& Applications 2: 67-72.

30. Ishikawa $\mathrm{S}$, Ishimaru $\mathrm{Y}$, Igura $\mathrm{M}$, Kuramata $\mathrm{M}$, Abe $\mathrm{T}$, et al. (2012) "Ion-beam irradiation, gene identification, and marker-assisted breeding in the development of lowcadmium rice". Proc Natl Acad Sci USA 109: 19166e19171.

31. Ishimaru Y, Takahashi R, Bashir K, Shimo H, Senoura T, et al. (2012) "Characterizing the role of rice NRAMP5 in manganese, iron and cadmium transport". Sci Rep 2: 989993.

32. Hui Li, Ming Hung Wong (2017) "Cadmium in rice: Transport mechanisms, influencing factors, and minimizing measures". Environmental Pollution 224: 622-630.

33. Bermudez GMA, Jasan R, Pla R, Pignata ML (2012) "Heavy metals and trace elements in atmospheric fallout: their relationship with topsoil and wheat element composition". J Hazard Mater 213: 447-e456.

34. Liu F, Liu XN, Ding C, Wu L (2015) "The dynamic simulation of rice growth parameters under cadmium stress with the assimilation of multi-period spectral indices and crop model". Field Crop Res 183: 225-234.

35. Arao T, Kawasaki A, Baba K, Mori S, Matsumoto S (2009) "Effects of water management on cadmium and arsenic accumulation and dimethylarsinic acid concentrations in Japanese rice". Environ 43: 9361-9367.

36. de Livera J, McLaughlin MJ, Hettiarachchi GM, Kirby JK, Beak DG (2011) "Cadmium solubility in paddy soils: effects of soil oxidation, metal sulfides and competitive ions". Sci Total Environ 409: 1489-1497.

37. Sun L, Chen S, Chao L, Sun TH (2007) "Effects of flooding on changes in Eh, $\mathrm{pH}$ and speciation of cadmium and lead in contaminated soil. Bull". Environ Contam Toxicol 79: 514-518.

38. Sebastian A, Prasad MNV (2015) "Iron- and manganeseassisted cadmium tolerancein Oryza sativa L.: lowering of rhizotoxicity next to functional photosynthesis Planta". Planta 241: 1519-1528.

39. Scagel IN, Dunn CE, Hall GEM, Scagel RK (1993) "Applied biogeochemcial porpsecting in Forested Terraine, Short course notes, Association of exploration chemists" 1993: 200.

40. Haglund B, Ryckenberg K, Selinus O, Dahlquist G (1996) "Evidence of a relationship between childhood-onset type I diabetes and low groundwater concentration of zinc". Diabetes Care 19: 873-875.

41. Borovicka J, Randa Z, Jelinek E (2006) "Gold content of ectomycorrhizal and sobprobic macrofungi an update", Journal of Physics, Conference Series 41: 169-173.

42. Borovicka J, Randa Z, Jelinek E (2006) “Antimony content of macrofungi from clean and polluted areas, chemosphere" 64: 1837-1844.

43. Lepp NW (1997) "Uptake and accumulation of metals in bacteria and fungi in Adriano": D.C., and col.: (1997). Biogeochemistry of trace metals, CRC Press, Boca Raton FL, 513FL: 513.

44. Ziarati P, Vambol V, Vambo S (2020) "Use of inductively coupled plasma optical emission spectrometry detection in determination of arsenic bioaccumulation in Trifolium pratense L. from contaminated soil. Ecological Questions" 31: 1-11.

45. Dang C, Chou WC, Adler R (2001) "Journal of Clinical Investigation in Arsenic's cancer paradox resolved", New Scientist 108: 1.

46. André FS Amaral, Miquel Porta, Debra T Silverman, Roger L Milne, Manolis Kogevinas, et al. (2012) "Pancreatic cancer risk and levels of trace elements". Gut 61: 1583-1588.

47. Garreau-Balandier I, Lefebvre M, Jacquard S, Caillat S, Cruz-Rodriguez L, et al. (2019) "A comprehensive approach to determining BER capacities and their change with aging in Drosophila melanogaster mitochondria by oligonucleotide microarray". A J Trace Elem Med Biol 54: 226-231.

48. Cruz-Rodriguez L, Zayas-Tamayo AM, Sanchez Batista L, Lambert-Brown D, Hochwimmer B, et al. (2020) "A Novel vaccine candidate with double antiviral activity against the HIV-1 and Covid-19": International Journal of Infectious Diseases and Research 2020: 1-6.

49. Cruz-Rodriguez L, Cruz-Rodriguez LD, Sanchez Batista L, Hochwimmer B (2020) "Calculation of Fusion Stability of [DNA or RNA] - Peptide (FS) Algorithm *CruzRodriguez*”. JB \& Bio Engine 2: 1-6.

Copyright: (O2020 CRUZ-RODRIGUEZ Luis. This is an open-acces article distributed under the terms of the Creative Commons Attribution License, which permits unrestricted use, distribution, and reproduction in any medium, provided the original author and source are credited. 